\title{
CARACTERIZAÇÃO DA ÁGUA DE AÇUDES COM PEIXES NO SEMIÁRIDO PERNAMBUCANO
}

\author{
Water characterization from waterbodies with fish in the semi-arid
}

\author{
Valdívia Thais Alves de Lima ${ }^{[a]}$, Daniela Ferraz Bacconi Campeche ${ }^{[b]}$, \\ Lucio Alberto Pereira ${ }^{[c]}$
}

\author{
[a] Bióloga da Embrapa Semiárido, Petrolina, PE - Brasil, e-mail: limathais@hotmail.com \\ [b] Bióloga em Ciência Animal, Pesquisadora da Embrapa Semiárido, Petrolina, PE-Brasil, e-mail:daniela.campeche@cpatsa.embrapa.br \\ ${ }^{[c]}$ Ecólogo em Geociências e Meio Ambiente, Pesquisador da Embrapa Semiárido, Petrolina, PE - Brasil, e-mail: \\ lucio.ap@cpatsa.embrapa.br
}

\begin{abstract}
Resumo
O presente estudo teve como objetivo avaliar e comparar as características físico-químicas da água de dois açudes, Manga-Nova e Federação, localizados no município de Petrolina, PE, povoados com peixes tilápia (Oreochromis niloticus) e tambaqui (Colossoma macropomum), no período de abril a outubro de 2007 e 2008. Foram realizadas coletas quinzenais de amostras de água, em diferentes pontos do açude, para as análises de ortofosfato $(\mathrm{mg} / \mathrm{L}), \mathrm{N}$-amoniacal $(\mathrm{mg} / \mathrm{L})$, nitrito $(\mathrm{mg} / \mathrm{L})$, alcalinidade total $\left(\mathrm{mg} / \mathrm{L} \mathrm{CaCO}_{3}\right)$ e dureza total $\mathrm{Ca}++\left(\mathrm{mg} / \mathrm{L} \mathrm{CaCO}_{3}\right)$, além da realização da leitura dos parâmetros: oxigênio dissolvido $(\mathrm{mg} / \mathrm{L})$, temperatura $\left({ }^{\circ} \mathrm{C}\right), \mathrm{pH}$, condutividade elétrica $(\mathrm{mS} / \mathrm{cm})$ e transparência $(\mathrm{cm})$. Os parâmetros físico-químicos que tiveram maior variação nos anos estudados foram: condutividade elétrica, alcalinidade total, dureza total e transparência da água. O açude Manga-Nova apresentou uma lâmina d'água maior que a do açude Federação, sendo, portanto, mais adequado para o povoamento de peixes. $\mathrm{O}$ açude Federação apresentou menor transparência da água, por esta se mostrar turva. Concluiu-se, a partir dos resultados obtidos, que é possível o aproveitamento da água de açudes dependentes de chuva para a produção de alimento proteico como forma de enriquecimento alimentar para comunidades carentes do Semiárido brasileiro, desde que a qualidade da água atenda aos parâmetros ideais para o desenvolvimento dos peixes.
\end{abstract}

Palavras-chave: Ambiente aquático. Limnologia. Parâmetros físico-químicos. Qualidade da água.

Rev. Acad., Ciênc. Agrár. Ambient., Curitiba, v. 7, n. 4, p. 395-405, out./dez. 2009 


\begin{abstract}
The aim of this study was to evaluate and compare the physical and chemical water characteristics of two waterbodies, Manga-Nova and Federação, located in Petrolina, PE, with tilapia (Oreochromis sp.) and tambaqui (Colossoma macropomum). Samples were collected from April trough October, in 2007 and 2008. Water samples were collected from three different points of the ponds to assess the levels of: orthophosphate $(\mathrm{mg} / \mathrm{L})$, ammonia-N $(\mathrm{mg} / \mathrm{L})$, nitrite $(\mathrm{mg} / \mathrm{L})$, total alkalinity $(\mathrm{mg} / \mathrm{L} \mathrm{CaCO})$ and total hardness $\mathrm{Ca}++\left(\mathrm{mg} / \mathrm{L} \mathrm{CaCO}{ }_{3}\right)$. In addition to the analysis of the parameters: dissolved oxygen ( $\mathrm{mg} / \mathrm{L})$, temperature $\left({ }^{\circ} \mathrm{C}\right), \mathrm{pH}$, electrical conductivity ( $\mu \mathrm{S} /$ $\mathrm{cm})$ and transparency $(\mathrm{cm})$. The parameters that had a greater difference in the years studied were: electrical conductivity, total alkalinity, hardness and total transparency of the water. Manga-Nova had a water surface larger than Federação and therefore it is more appropriate for fish raise as it has a larger quantity of water throughout the year. Federação showed lower transparency of water. The conclusion is that it is possible to use water bodies rain fed to produce protein as enriching food to needy communities of the Brazilian semi-arid, once the water quality meets the optimum for fish development.
\end{abstract}

Keywords: Aquatic environment. Limnology. Physic-chemical parameters. Water quality.

\title{
INTRODUÇÃO
}

Para o crescimento e a sobrevivência dos animais aquáticos é necessário manter as características físicas e químicas da água dentro dos limites toleráveis pelos mesmos, condições essas que dependem de fatores ambientais. Segundo Castagnolli (1992), destacam-se os fatores climatológicos, que exercem influência direta sobre a temperatura, cor, turbidez e condutividade nas águas, e essas, por sua vez, podem alterar características químicas como a riqueza em nutrientes ( $\mathrm{N} \mathrm{e} \mathrm{P),} \mathrm{pH,} \mathrm{alcalinidade,}$ dureza, teor dos gases $\mathrm{O}_{2}$ e CO 2 dissolvidos, influenciando diretamente a produção primária (fitoplâncton), secundária (zooplâncton) e, como consequência, os peixes.

As águas naturais apresentam grandes variações nas suas características físicas e químicas. Essas são determinadas pela localização geográfica do corpo d'água, pelas características geológicas da região em que se situa a vegetação que circunda suas margens e, também, pela influência da ação humana sobre esses ecossistemas aquáticos (CASTAGNOLLI, 1992).

É fundamental o conhecimento das características das águas para a sobrevivência de organismos aquáticos. O presente trabalho teve como objetivo avaliar e comparar as características físico-químicas da água de dois açudes, Manga-Nova e Federação, povoados com peixes tilápia (Oreochromis niloticus) e tambaqui (Colossoma macropomum).

\section{MATERIAIS E MÉTODOS}

\section{Área de estudo}

O município de Petrolina localiza-se a uma latitude $08^{\circ} 59^{\prime} 49^{\prime \prime}$ sul e a uma longitude $40^{\circ}$ 16’ 19" oeste (Figura 1), numa altitude de 300 metros. O período chuvoso inicia-se em novembro, com término em abril. A precipitação média anual é de 431,8 $\mathrm{mm}$. 


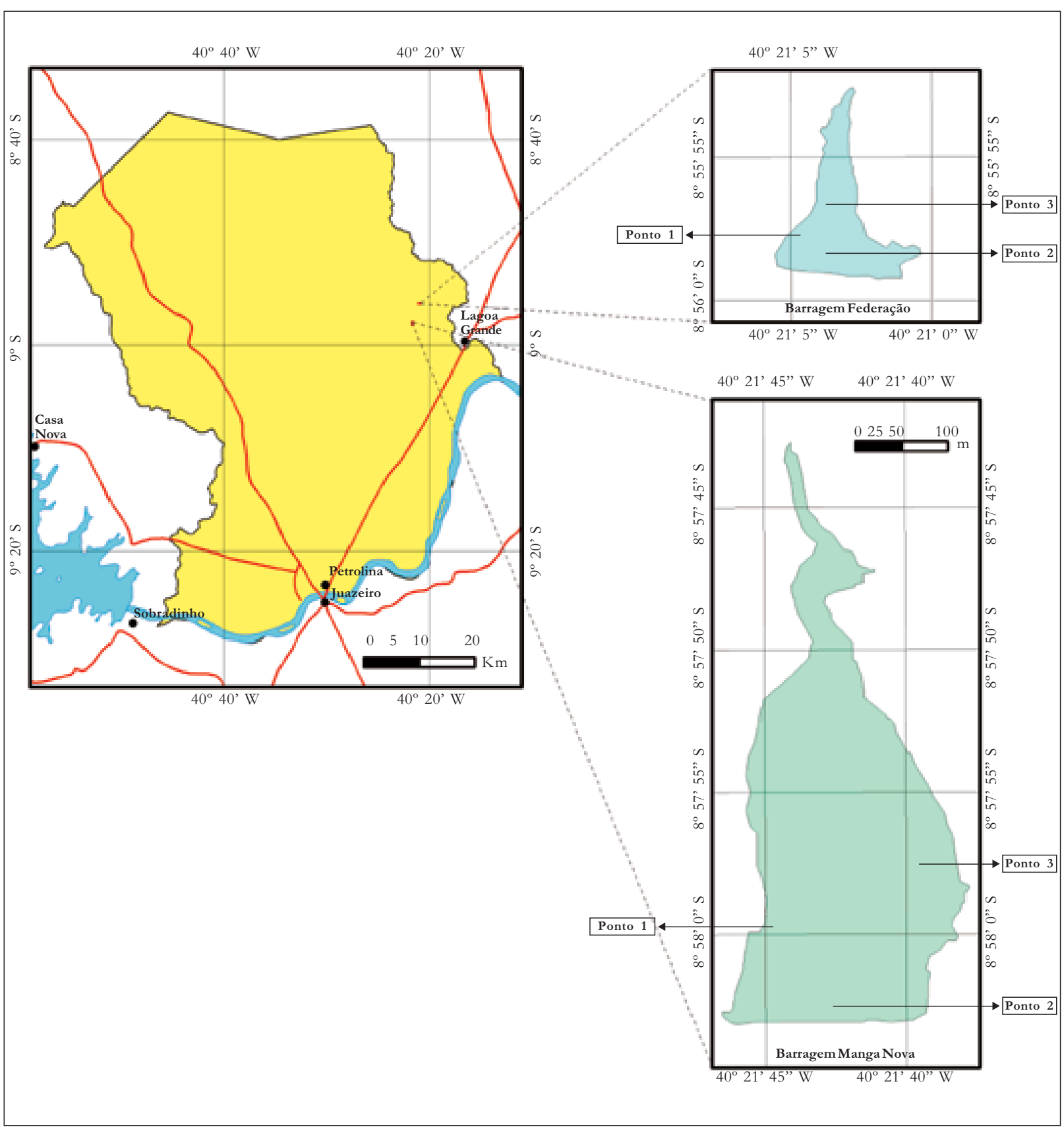

FIGURA 1 - Mapa de localização dos açudes Manga-Nova e Federação, Petrolina-PE (CAMPECHE et al., 2007) 
Os açudes Manga-Nova (MN) e Federação (F) estão localizados no município de Petrolina, PE. O MN está a $40^{\circ} 21$ ' $45^{\prime \prime}$ 'W e $8^{\circ} 58^{\prime} 0^{\prime \prime}$ ' S, com uma área média de $33.840 \mathrm{~m}^{2}$ e com perímetro médio de $1.277 \mathrm{~m}$. O F está a $40^{\circ} 21^{\prime} 5^{\prime \prime}$ 'W e $8^{\circ} 55^{\prime} 55^{\prime \prime} \mathrm{S}$, com uma área média de $4.550 \mathrm{~m}^{2}$ e com perímetro médio de $322 \mathrm{~m}$. Ambos pertencem à área de assentamento agrário de mesmo nome, onde vivem comunidades formadas por 25 famílias que dependem dessa água para consumo doméstico e dessedentação animal.

\section{Coleta e amostragem}

O estudo foi conduzido, durante o período de abril a outubro de 2007 e 2008, que corresponde à estação de seca. As coletas de amostras de água foram realizadas quinzenalmente em três pontos distintos, no período da manhã, por volta das 8 horas. A profundidade dos pontos de coleta de cada açude em relação à coluna d'água era em média de $10 \mathrm{~cm}$. O resultado de cada parâmetro físico-químico foi obtido por meio da média dos valores dos três pontos de coleta de amostra de cada açude. Em cada coleta foi realizada a leitura de parâmetros físico-químicos utilizando medidores automáticos portáteis (WTW) para obtenção dos valores: oxigênio dissolvido - OD $(\mathrm{mg} / \mathrm{L})$, temperatura $\left({ }^{\circ} \mathrm{C}\right), \mathrm{pH}$, condutividade elétrica $(\mathrm{mS} / \mathrm{cm})$. A transparência da água $(\mathrm{cm})$ foi avaliada utilizando-se o disco de Secchi.

As análises físico-químicas dos seguintes parâmetros: ortofosfato $(\mathrm{mg} / \mathrm{L})$, nitrogênio amoniacal $(\mathrm{mg} / \mathrm{L})$, nitrito $(\mathrm{mg} / \mathrm{L})$, alcalinidade total $\left(\mathrm{mg} / \mathrm{L} \mathrm{CaCO}_{3}\right)$ e dureza total $\mathrm{Ca}^{++}(\mathrm{mg} / \mathrm{L}$ $\mathrm{CaCO} 3$ ) foram realizadas no Laboratório de Solos da Embrapa Semiárido. Todas as análises foram realizadas seguindo as normas do Standard Methods (APHA, 1992), em que dureza total e alcalinidade foram medidas por titulometria, e ortofosfato, nitrogênio amoniacal e nitrito, por colometria em um espectrofotômetro de UV visível Quimis.

Para a morfometria e batimetria dos açudes foram utilizados GPS marca Garmin, modelo Etrex, e uma trena plástica de $5 \mathrm{~m}$. A morfometria foi obtida contornando a margem com o GPS. A batimetria foi realizada por meio de medidas de profundidade associadas ao georreferenciamento de cada ponto. O procedimento adotado foi a demarcação de linhas paralelas ao vertedouro (barramento), distantes aproximadamente $3 \mathrm{~m}$ entre cada, e em cada linha dessa foram medidas a profundidade e a posição geográfica de pontos distantes $4 \mathrm{~m}$ entre si. Para a geração do contorno e cálculo da área utilizou-se o software ArcGIS versão 9.1, com a área sendo calculada pela projeção utilizada pelo IBGE: Cylindrical Equal-Area. Com os dados da batimetria gerou-se o modelo digital do terreno (MDT), utilizando o método geoestatístico de Krigagem, com software Surfer versão 7.0.

\section{RESULTADOS E DISCUSSÕES}

Analisando os resultados obtidos para os parâmetros físico-químicos da água do açude Manga-Nova (Tabela 1) e Federação (Tabela 2), observou-se que o oxigênio dissolvido (OD) dos açudes $\mathrm{MN}$ e $\mathrm{F}$ apresentaram valores dentro da faixa de sobrevivência para peixes. Os menores valores foram encontrados no início das coletas de cada ano. Já os maiores valores foram encontrados no período de julho, para o açude F, e no período de julho e agosto, no açude MN. Essas oscilações devem-se à mudança de temperatura durante o ano: quanto menor a temperatura, maior será a quantidade de oxigênio dissolvido. Segundo Proença e Bittencourt (1994), de $3 \mathrm{mg} /$ L a $5 \mathrm{mg} / \mathrm{L}$ tem-se um teor suportável de OD, e acima de $5 \mathrm{mg} / \mathrm{L}$ tem-se níveis ótimos, estando os valores encontrados no presente trabalho de acordo com esses autores. Macêdo et al. (2007) encontraram taxas de OD apresentando valores mínimos de 3,80 mg/L, e máximos de 4,92 $\mathrm{mg} / \mathrm{L}$, em um açude localizado na Bacia do Potengi, Rio Grande do Norte. Chellappa et al. (2008) encontraram para OD os valores mínimos de 3,17 mg/L, em dezembro de 2004, e máximos de 7,60 $\mathrm{mg} / \mathrm{L}$, em junho de 2005, no açude público de Cruzeta, Rio Grande do Norte. Os menores valores estão semelhantes aos encontrados tanto no açude MN como no F.

Rev. Acad., Ciênc. Agrár. Ambient., Curitiba, v. 7, n. 4, p. 395-405, out./dez. 2009 


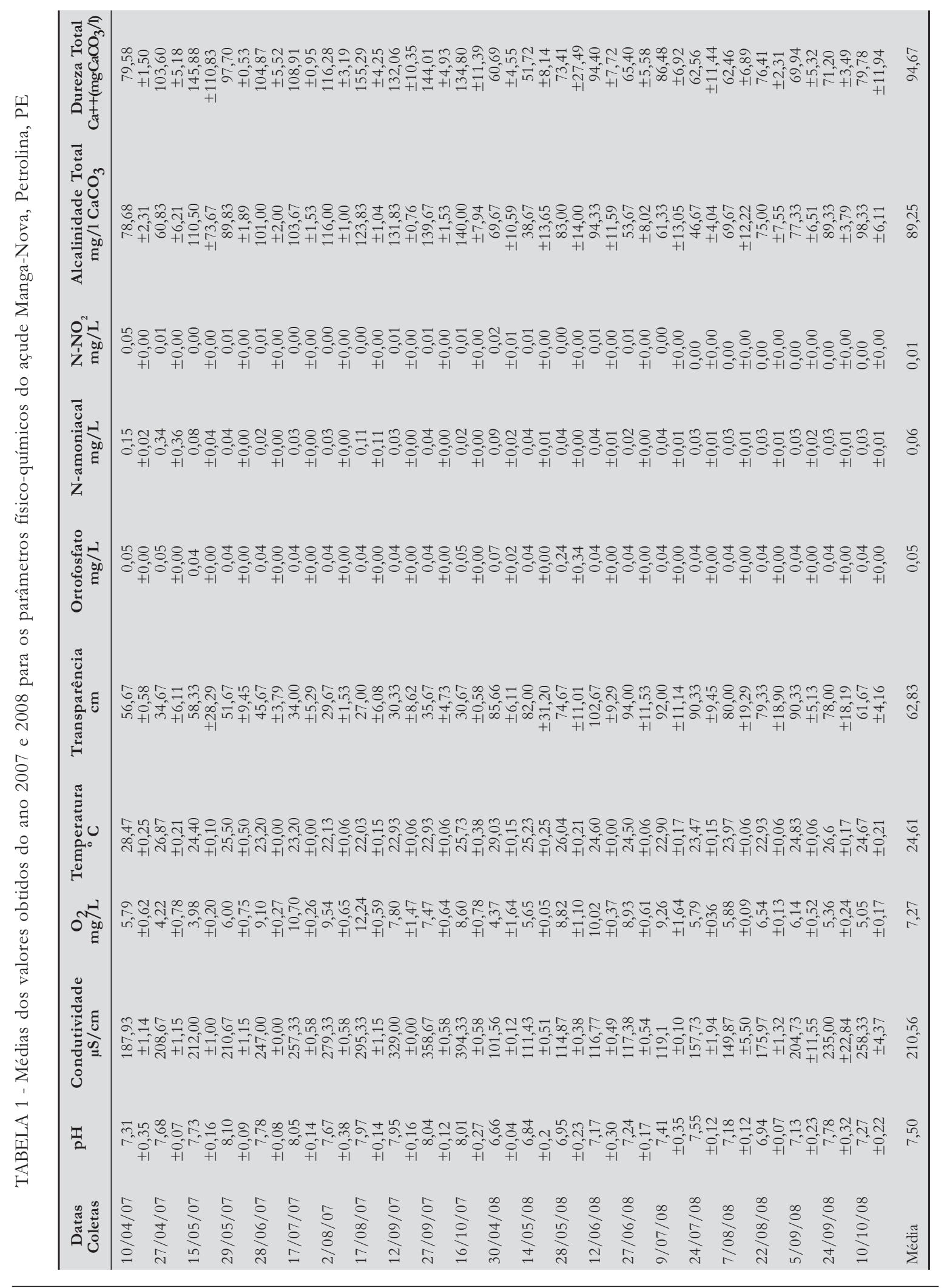

Rev. Acad., Ciênc. Agrár. Ambient., Curitiba, v. 7, n. 4, p. 395-405, out./dez. 2009 


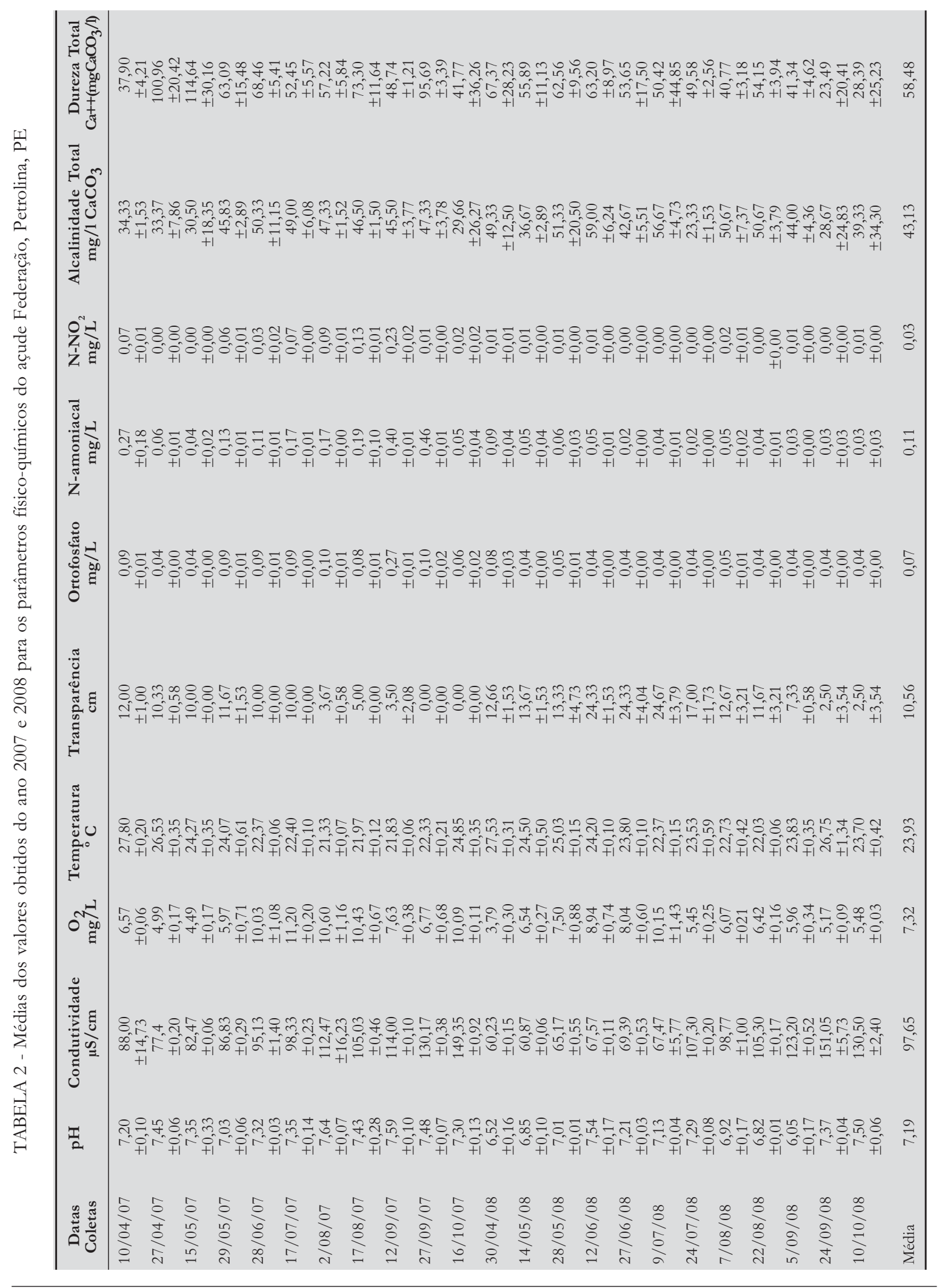

Rev. Acad., Ciênc. Agrár. Ambient., Curitiba, v. 7, n. 4, p. 395-405, out./dez. 2009 
Os maiores e menores valores de temperatura nos açudes MN (Tabela 1) e F (Tabela 2) estão dentro da faixa ideal de conforto térmico para crescimento e reprodução dos peixes (CAMPECHE et al., 2007). A temperatura mínima encontrada no açude $\mathrm{F}$ apresenta similaridade com a encontrada por Sampaio e López (2003) na represa de Três Marias (MG), que foi de $21,4^{\circ} \mathrm{C}$. Wright (1981) encontrou temperatura mínima de $22,30^{\circ} \mathrm{C}$ e máxima de $28,6^{\circ} \mathrm{C}$, estando esses valores próximos aos encontrados no açude MN. Silva et al. (2007) encontraram temperaturas mínimas e máximas de $25,91^{\circ} \mathrm{C}$ e $30,23^{\circ} \mathrm{C}$, para a Enseada, no Baixo Rio das Mortes, Mato Grosso.

$\mathrm{O} \mathrm{pH}$ do $\mathrm{MN}$ apresentou valores neutros, com pequenas oscilações para o alcalino e para $\mathrm{o}$ ácido (Tabela 1). $\mathrm{O}$ pH do açude $\mathrm{F}$ (Tabela 2) foi quase que totalmente neutro, com leves oscilações para o ácido. Segundo Tavares (1994) a faixa ideal de $\mathrm{pH}$ para criação de peixe está entre 6,5 a 9,5; assim sendo, os valores obtidos no presente estudo estão no intervalo de variação considerado como adequado. Valores encontrados por Wright (1981) para o açude de Bodocongó, PB, obteve variação de 7,20 a 7,85, e Roberto et al. (2009) encontraram em uma planície de inundação do Alto Rio Paraná-PR valores de $\mathrm{pH}$ próximo ao neutro, mostrando-se similares aos encontrados no presente estudo. Diferentes valores foram encontrados por Macêdo et al. (2007), que obtiveram mínima de 5,90 e máxima de 6,79 para o açude de abastecimento da Escola Agrícola de Jundiaí, localizado no município de Macaíba, região metropolitana de Natal, RN.

A condutividade elétrica dos açudes MN (Tabela 1) e F (Tabela 2) apresentou valores altos, indicando um aumento de concentração de sais devido ao menor volume de água, resultado influenciado também pelas características pedológicas e geológicas da região. Pinto et al.(2003) encontraram na água de infiltração a condutividade de $123 \mu \mathrm{S} / \mathrm{cm}$, e para a água de escoamento artificial, a condutividade em torno de $74 \mu \mathrm{S} / \mathrm{cm}$ - esses valores são referentes à Lagoa Feia e ao Rio São Francisco, Minas Gerais. Quando a água apresenta alta condutividade, provavelmente contém grande quantidade de nutrientes dissolvidos (CAMARGO; VALENTI, 1990), sendo uma maneira de avaliar sua disponibilidade nos ecossistemas aquáticos (CASTAGNOLLI, 1992).

A transparência da água do açude MN (Tabela 1) foi alta quando comparada com a do açude F (Tabela 2), que apresentou baixa incidência de penetração dos raios solares na coluna d'água. A variação da transparência da água é explicada pelo aumento da quantidade de partículas em suspensão, que pode ser observada visualmente, devido à regressão da lâmina d'água. Segundo Cyrino e Kubitza (1996), visibilidades inferiores a $30 \mathrm{~cm}$ estão associadas a problemas de falta de oxigênio no período noturno, pois é usado o oxigênio produzido pelo fitoplâncton durante o dia. Silva et al. (2007) encontraram para a transparência da água a média de 101,5 $\mathrm{cm}$ na Enseada e de $70,4 \mathrm{~cm}$ no Canal do Rio (Mato Grosso), sem variação significativa entre os dois ambientes, enquanto Gurgel (1981) encontrou a maior transparência, de $275 \mathrm{~cm}$, e a menor, de $75 \mathrm{~cm}$, no açude Amanari (Ceará), devido à suspensão do material argiloso conduzido pelas chuvas.

Observando os valores de ortofosfato do açude MN (Tabela 1), verificou-se que nos dois anos estudados os valores foram baixos, apresentando pico no mês de maio de 2008. No açude F (Tabela 2) os valores também foram baixos, sendo o pico observado em setembro de 2007. Os valores obtidos nos açudes são referentes a um lago eutrófico (ESTEVES, 1998). Amâncio et al. (2005) obtiveram valores de ortofosfatos entre 0,00 a $0,61 \mathrm{mg} / \mathrm{L}$ no açude Pentecoste, Ceará. Essas concentrações diminuíram com a elevação do volume d'água do açude.

A amônia dos açudes MN (Tabela 1) e F (Tabela 2) apresentaram valores baixos. Valores elevados da amônia são tóxicos, podendo levar à mortalidade dos peixes. De acordo com Arana (1997), esses valores estão abaixo do encontrado em viveiros de água doce. Os valores encontrados no presente estudo demonstram que as concentrações de amônia estiveram dentro do nível tolerado pelos peixes, que, segundo Tavares (1994), é de 0,6 a 2,0 mg. $\mathrm{L}^{-1}$. Amâncio et al. (2005) encontraram o teor mínimo e máximo de amônia total de $0,0122 \mathrm{mg} / \mathrm{L}$ e $1,12 \mathrm{mg} / \mathrm{L}$ para o açude Pentecoste, Ceará. Esses valores demonstram que as concentrações de amônia mantiveram-se dentro do nível tolerado pelos peixes.

Os valores de nitrito para os açudes MN (Tabela 1) e F (Tabela 2) tiveram a maioria dos

Rev. Acad., Ciênc. Agrár. Ambient., Curitiba, v. 7, n. 4, p. 395-405, out./dez. 2009 
resultados nulos (zero), pois é uma forma intermediária de nitrogênio inorgânico entre nitrato e amônia. Para Tavares (1994), os valores tolerados de nitrito para peixes são de até $0,5 \mathrm{mg} / \mathrm{L}$; contudo, os valores encontrados no presente estudo estão abaixo do valor permitido. Amâncio et al. (2005) encontraram teores de nitrito entre 0,0066 e $0,0726 \mathrm{mg} / \mathrm{L}$ para o açude Pentecoste, Ceará, concluindo que houve uma diluição dos compostos nitrogenados.

No açude MN (Tabela 1) a alcalinidade apresentou grande variação durante o tempo de estudo. No açude F (Tabela 2) a variação encontrada foi menor que a do açude MN. Segundo Proença e Bittencourt (1994), a faixa ideal é entre 20 e $300 \mathrm{mg} / \mathrm{L}$. Tavares (1994) afirma que águas naturais normalmente contêm mais bicarbonato, que resultam da ionização do gás carbônico em águas saturadas com CO2. Contudo, os valores encontrados no presente estudo estão dentro da faixa estabelecida para ótima sobrevivência de peixes.

A dureza total do açude MN (Tabela 1) e F (Tabela 2) também apresentaram grande variação de 2007 a 2008, sendo que os valores mínimos e máximos encontrados para o açude F foram menores que os encontrados no açude MN. Segundo Boyd (1990) esses valores classificam a água como branda (até $75 \mathrm{mg} / \mathrm{L}$ ) a moderadamente dura (até $150 \mathrm{mg} / \mathrm{L}$ ), mas não é um impedimento para o crescimento dos peixes. Brito et al. (2005) encontraram valores de 74,00, 161,67, 100,00 e 170,00 Ca++(mg/L $\mathrm{CaCO}_{3}$ ) para açudes nos municípios de Petrolina e Ouricuri, PE, e Canudos e Uauá, BA, respectivamente. Valores de dureza total acima de $20 \mathrm{Ca}++\left(\mathrm{mg} / \mathrm{L} \mathrm{CaCO}_{3}\right)$ indicam águas de adequado poder tampão (CYRINO; KUBITZA, 1996).

Analisando a regressão da lâmina d'água dos açudes MN e F (Figuras 2, 3, 4 e 5), pode-se observar que no ano 2008 ambos açudes armazenaram maior quantidade de água que no ano de 2007. Contudo, apesar dos açudes serem temporários, eles suportam um grande volume durante o ano, permanecendo com água para o ano subsequente.

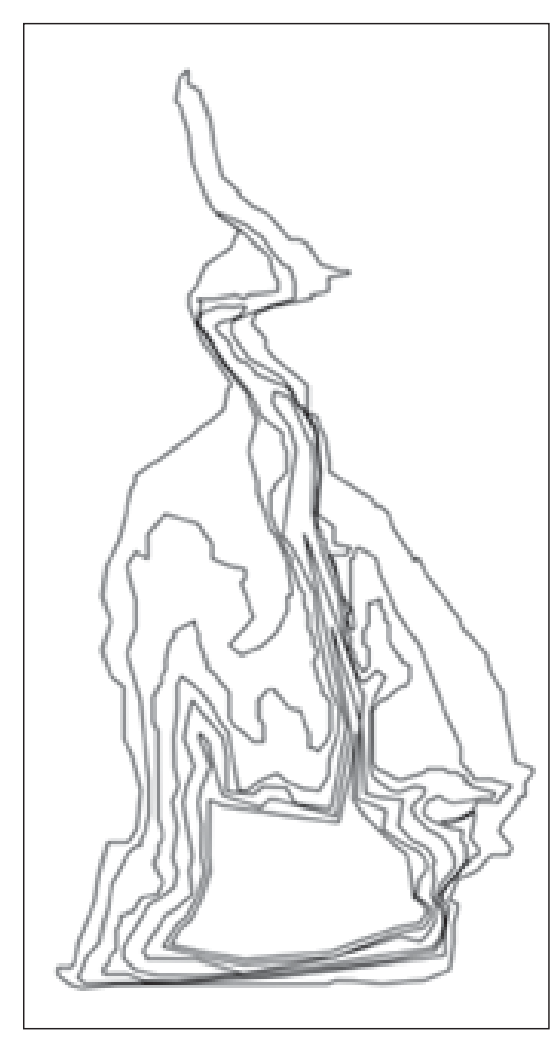

\begin{tabular}{ccc}
\hline \multicolumn{3}{c}{ AÇUDE MANGA-NOVA } \\
DATA & ÁREA (m ${ }^{2}$ ) & PERÍMETRO (m) \\
\hline $10 / 04 / 07$ & 79.660 & 1.718 \\
$15 / 05 / 07$ & 54.965 & 1.891 \\
$28 / 06 / 07$ & 35.178 & 1.751 \\
$17 / 07 / 07$ & 24.976 & 1.267 \\
$02 / 08 / 07$ & 17.808 & 991 \\
$12 / 09 / 07$ & 13.434 & 787 \\
$16 / 10 / 07$ & 10.862 & 531 \\
\hline
\end{tabular}

FIGURA 2 - Regressão da lâmina d'água do açude Manga-Nova no ano 2007 (CAMPECHE et al., 2007)

Rev. Acad., Ciênc. Agrár. Ambient., Curitiba, v. 7, n. 4, p. 395-405, out./dez. 2009 


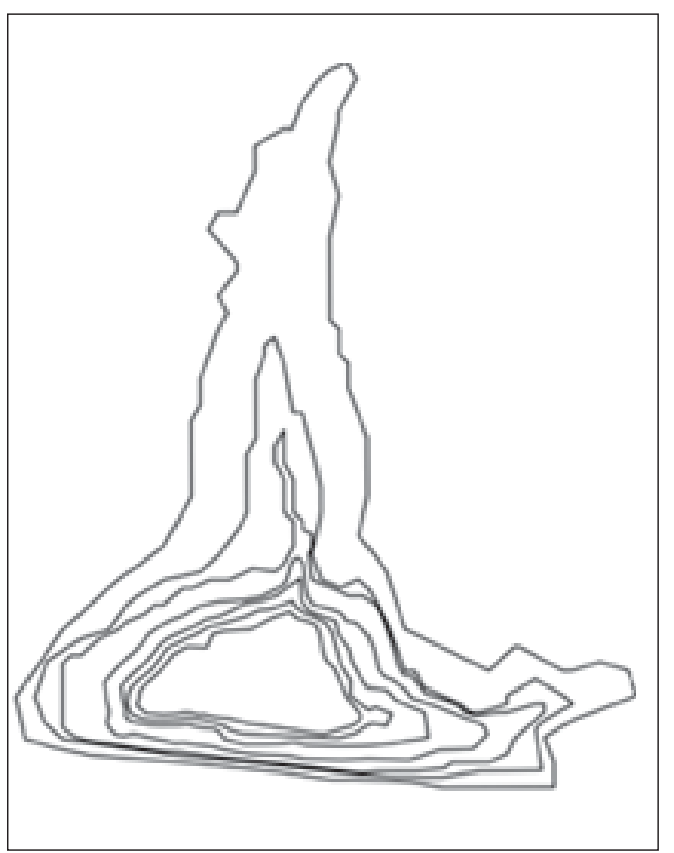

\begin{tabular}{ccc}
\hline \multicolumn{3}{c}{ AÇUDE FEDERAÇÃO } \\
DATA & ÁREA (m $\left.{ }^{2}\right)$ & PERÍMETRO (m) \\
\hline 10/04/07 & 11.195 & 652 \\
$15 / 05 / 07$ & 7.501 & 465 \\
$28 / 06 / 07$ & 4.725 & 385 \\
$17 / 07 / 07$ & 3.686 & 218 \\
$02 / 08 / 07$ & 1.998 & 199 \\
$12 / 09 / 07$ & 1.553 & 181 \\
$16 / 10 / 07$ & 1.191 & 150 \\
\hline
\end{tabular}

FIGURA 3 - Regressão da lâmina d'água do açude Federação no ano 2007 (CAMPECHE et al., 2007)

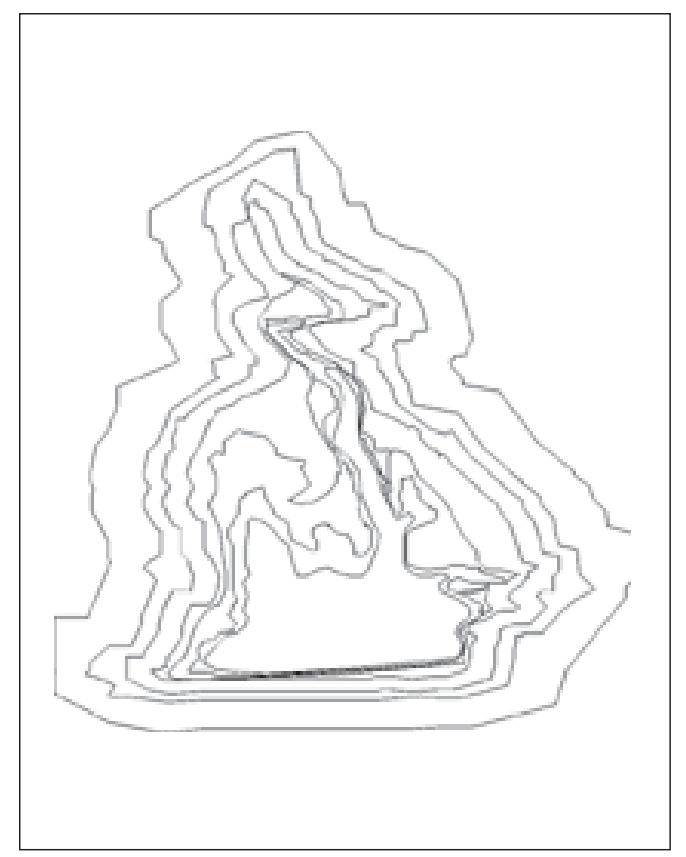

\begin{tabular}{ccc}
\hline \multicolumn{3}{c}{ AÇUDE MANGA-NOVA } \\
DATA & ÁREA (m ${ }^{2}$ ) & PERÍMETRO (m) \\
\hline 30/04/08 & 212.999 & 2.258 \\
$14 / 05 / 08$ & 135.904 & 1.959 \\
$12 / 06 / 08$ & 110.183 & 1.841 \\
$09 / 07 / 08$ & 79.660 & 1.718 \\
$07 / 08 / 08$ & 55.060 & 1.891 \\
$05 / 09 / 08$ & 36.386 & 1.751 \\
$10 / 10 / 08$ & 25.325 & 1.267 \\
\hline
\end{tabular}

FIGURA 4 - Regressão da lâmina d'água do açude MangaNova no ano 2008 (CAMPECHE et al., 2007)

Rev. Acad., Ciênc. Agrár. Ambient., Curitiba, v. 7, n. 4, p. 395-405, out./dez. 2009 


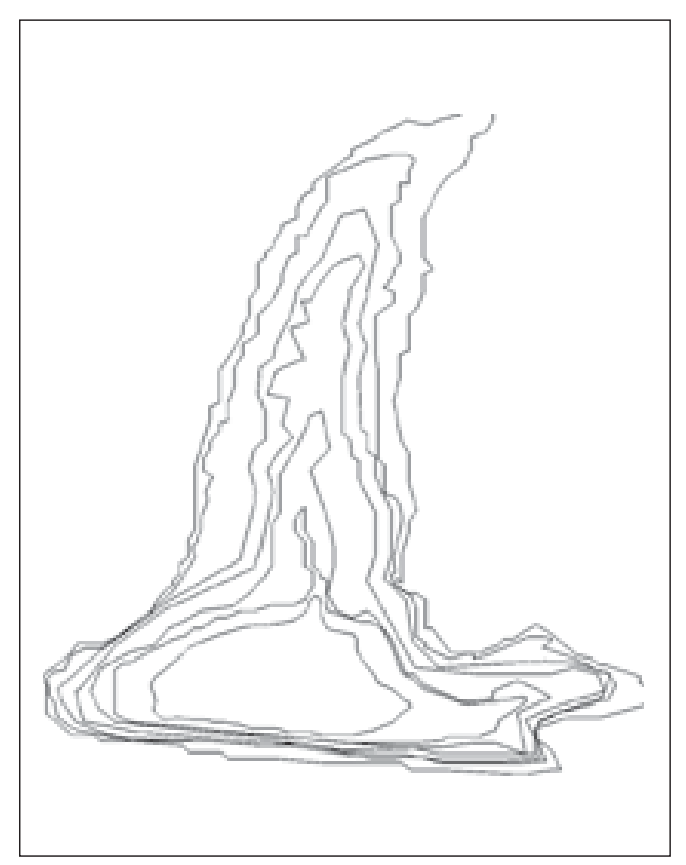

\begin{tabular}{ccc}
\hline \multicolumn{3}{c}{ AÇUDE FEDERAÇÃO } \\
DATA & ÁREA (m $\left.{ }^{2}\right)$ & PERÍMETRO (m) \\
\hline $30 / 04 / 08$ & 19.604 & 865 \\
$14 / 05 / 08$ & 15.894 & 783 \\
$12 / 06 / 08$ & 12.465 & 687 \\
$09 / 07 / 08$ & 11.195 & 652 \\
$07 / 08 / 08$ & 6.091 & 465 \\
$05 / 09 / 08$ & 4.502 & 385 \\
$10 / 10 / 08$ & 2.622 & 218 \\
\hline
\end{tabular}

FIGURA 5 - Regressão da lâmina d'água do açude Federação no ano 2008 (CAMPECHE et al., 2007)

\section{CONCLUSÕES}

Diante dos resultados obtidos, pode-se concluir que é possível o aproveitamento da água de açudes dependentes de chuva para a produção de alimento proteico, como forma de enriquecimento alimentar para comunidades carentes do Semiárido brasileiro, desde que a qualidade da água atenda às exigências básicas para o desenvolvimento de peixes, o que é o caso do açude Manga-Nova, mas não do Federação.

\section{REFERÊNCIAS}

AMANCIO, A. L. L. et al. Balanço de nutrientes da água do açude Pentecoste (Pentecoste, Ceará, Brasil) no período de março a dezembro de 2002. Revista Ciência Agronômica, Fortaleza, v. 36, n. 1, p. 44-52, 2005.

AMERICAN PUBLIC HEALTH ASSOCIATION - APHA. Standard methods for examination of water and wastewater. 18 th ed. Washington: APHA, 1992.

ARANA, L. V. Princípios químicos de qualidade da água em aqüicultura. Florianópolis: Ed. da UFSC, 1997.

BRITO, L. T. L. et al. Avaliação da qualidade das águas de açudes nos municípios de Petrolina e Ouricuri, PE, e Canudos e Uauá, BA: estudo de caso. In: SIMPÓSIO BRASILEIRO DE CAPTAÇÃO E MANEJO DE ÁGUA DE CHUVA, 5., 2005, Teresina. Anais... Teresina: ABCMAC, 2005. 1 CD-ROM.

BOYD, C. Water quality in ponds for aquaculture. Alabama: Alabama Agricultural Experiment Station, Auburn University, 1990. 
CAMPECHE, D. F. B. et al. Caracterização limnológica e morfometria de açudes dependentes de chuva povoados com tambaqui (Colossoma macropomum) no Semi-Árido Nordestino. In: CONGRESSO BRASILEIRO DE PRODUCCÃO DE PEIXES NATIVOS DE ÁGUA DOCE, ENCONTRO DE PISCICULTORES DE MATO GROSSO DO SUL, 1., 2007, Dourados. Anais... Dourados: Embrapa Agropecuária Oeste, 2007. 1 CD-ROM. (Embrapa Agropecuária Oeste. Documentos, 87).

CASTAGNOLLI, N. Criação de peixes de água doce. Jaboticabal: Funep, 1992.

CAMARgO, A. F. M.; VALENTINI, W. C. Características físicas e químicas da água. In: CASTAGNOLLI, N.; PINTO, M. L. G. Piscicultura. Jaboticabal: UNESP/CA, 1990. p. 8-13.

CHELLAPPA, N. T. et al. Phytoplankton community and physical-chemical characteristics of water in the public reservoir of Cruzeta, RN, Brazil. Braz. J. Biol., v. 68, n. 3, p. 477-494, 2008. Disponível em: <http://www.scielo.br/pdf/bjb/v68n3/a04v68n3.pdf>. Acesso em: 25 jun. 2008.

CYRINO, J. E. P.; KUBITZA, F. Piscicultura. Cuiabá: Sebrae, 1996.

ESTEVES, F. A. Fundamentos de limnologia. Rio de Janeiro: Interciência; FINEP, 1998.

GURGEL, J. J. S. Aspectos limnológicos do açude Amanari em Maranguape, Ceará, Brasil. In: BRASIL. Departamento Nacional de Obras Contra Secas. Estudos físico-químicos. Fortaleza: DNOCS, 1981. p. 187-214. (2 Coletânea de Trabalhos Técnicos).

MACÊDO, H. R. et al. Estudo de parâmetros físico-químicos para a criação de camarão marinho Litopenaeus vannamei em água doce. In: CONGRESSO DE PESQUISA E INOVAÇÃO DA REDE NORTE NORDESTE DE EDUCAÇÃO TECNOLÓGICA, 2., 2007, João Pessoa. Anais... João Pessoa: CEFET-PB, 2007. 1 CR-ROM.

PINTO, M. T. C.; YU, L.-W.; BARBOSA, F. A. R. Dinâmica mineral na interfase terra-água no alto São Francisco. In: GODINHO, H. P.; GODINHO, A. L. (Org.). Águas, peixes e pescadores do São Francisco das Minas Gerais. Belo Horizonte: Ed. da PUC Minas, 2003. p. 51-69.

PROENÇA, C. E. M.; BITTENCOURT, P. R. L. Manual de piscicultura tropical. Brasília: IBAMA, 1994.

ROBERTO, M. C. et al. Limnology in the upper Paraná River floodplain: large-scale spatial and temporal patterns, and the influence of reservoirs. Brazilian Journal of Biology, São Carlos, v. 69 , n. 2, p. 717-725, 2009.

SAMPAIO, E. V.; LÓPEZ, C. M. Limnologias física, química e biológica da represa de Três Marias e do São Francisco. In: GODINHO, H. P.; GODINHO, A. L. (Org.). Águas, peixes e pescadores do São Francisco das Minas Gerais. Belo Horizonte: Ed. da PUC Minas, 2003. p. 71-92.

SILVA, E. F. et al. Fatores que influenciam a comunidade de peixes em dois ambientes no baixo Rio das Mortes, Planície do Bananal, Mato Grosso, Brasil. Revista Brasileira de Zoologia, Curitiba, v. 24, n. 2 , p. 482-492, 2007.

TAVARES, L. H. S. Limnologia aplicada à aqüicultura. Jaboticabal: Funep, 1994.

WRIGHT, S. Da física e da química das águas do nordeste do Brasil. In: BRASIL. Departamento Nacional de Obras Contra Secas. Boletim técnico/DNOCS, Fortaleza, v. 39, n. 1, p. 21-31, jan. 1981.

Recebido: 27/07/2008

Received: $07 / 27 / 2008$

Aprovado: 18/05/2009

Approved: 05/18/2009

Rev. Acad., Ciênc. Agrár. Ambient., Curitiba, v. 7, n. 4, p. 395-405, out./dez. 2009 